\title{
Removing the blinkers: what a process view learns about G2G information systems in Flanders.
}

\author{
Lies Van Cauter ${ }^{1}$, Monique Snoeck ${ }^{2}$, Joep Crompvoets ${ }^{1}$ \\ ${ }^{1}$ KU Leuven, Public Governance Insitute, Leuven, Belgium \\ (Lies.VanCauter, Joep.Crompvoets)@ soc.kuleuven.be \\ ${ }^{2} \mathrm{KU}$ Leuven, Research Centre for Management Informatics, Leuven, Belgium \\ Monique.Snoeck@kuleuven.be
}

\begin{abstract}
A major objective of government-to-government (G2G) egovernment is information sharing and connecting different islands of information. Various barriers impede this connection. Factor research provides a partial explanation of why so many G2G information systems fail. In this paper we take a broader perspective by applying process research to study eight recurrent problems of Flemish G2G IS in their dynamic context. We test whether Sauer's needs and support-power analysis framework can provide additional management insights compared to factor based project management. Our results, based on interviews and focus groups, show that process management is better qualified for dealing with the dynamic context and interactions of Flemish G2G IS.
\end{abstract}

Keywords. IS failure + G2G * process management + needs \& support power analysis

\section{Introduction}

Information necessary to provide better public services and to solve critical public problems is often not available within a single organisation [26], [34]. A major objective of e-government is information sharing and connecting different islands of information [31].

Information sharing at a government-to-government $(\mathrm{G} 2 \mathrm{G})$ level appears to be more complex and hence more prone to failure than in a single organisation [8]. Various barriers impede the connection of different islands of information. These barriers are not only of a technical nature but also of an economic, legal, political and management nature [23], [25].

The high degrees of G2G information systems (ISs) failure motivated practitioners as well as researchers to investigate the underlining problems [33]. Practitioners have conducted retrospectives such as project post-mortems, performance reviews, or lessons learned, while researchers have investigated the causes of failure, critical success/failure factors and approaches that contribute to project success. Despite intensive research in the last four decades, the degree of failure remains too high [7], [20]. Failure continues because of the tendency to let flops rest and go on [17] but also because of a too narrow focus on IS failure. 
For a long time positivistic factor-oriented research was the dominant focus when studying G2G IS failure. Researchers with this focus believe that G2G IS failure can be prevented if management can detect and eliminate the causal factors of failure [27]. Classical output of this research is a list of failure factors targeting IS managers. Eliminating failure factors does unfortunately not guarantee success because G2G IS projects are subject to dynamic interacting factors and stakeholders. Factor-oriented research however ignores the context and sees as such only a part of the IS failure puzzle. Because of this, no coherent explanation of the 'whys' and 'hows' can be obtained [30].

The narrow factor oriented focus has an influence on the way G2G IS projects are managed in practice. Project managers tend to focus on strict problem definitions, clear goals, tight time schedules and a predefined end product to minimize the risk of random events [10]. Output oriented models focus merely on the end product while ignoring the process [26]. Managers use lists of failure factors as a 'ready to use frame' to get grip on the situation. As explained above, this approach can never guarantee success because it is too simplistic to cope with the dynamic character of a G2G IS environment [5], [16]. Although attempts have already been undertaken to rethink project management, more research is still needed [10], [32].

Last year [6] appealed for more research with a broader focus on local contingencies and a dynamic environment. In order to professionalise G2G IS managers should become aware of the dynamic interactions between different stakeholders and the environment [11]. To get this broader focus, two shifts are needed: firstly, a shift from factor-oriented research to process research, and secondly, a shift from project management to process management.

The process perspective sees IS as fundamentally social, grounded in a specific context and dependent on contingent processes [18]. Process managers focus on interests, intergovernmental consensus building in different arenas and on potential chances or barriers in an IS's environment [10]. As such a process research and management focus might help to see another part of the IS failure puzzle.

Process research has sought to get beyond the factor approach and advanced various frameworks including the interactionist (e.g. Davis), interpretivist (e.g. Myers, Young or Walsham) and exchange perspective (e.g. Sauer) [23]. None of these are widely accepted, and we might wonder whether this is rightly or not. The authors of this article elaborate further on Sauer's work. Sauer [22] believes that the first step to raise practitioners' awareness about the process perspective (such as context and dynamic interactions), could be achieved by conducting a needs analysis and supportpower analysis. In this article we will conduct a needs and support analysis for 8 recurrent problems. These problems are distilled from experiences of Flemish (Belgium) G2G IS practitioners. Our research question is therefore:

$R Q$ : Can the needs and support-power analysis of Sauer provide additional insights for G2G IS management in Flanders?

The remaining of the paper is organised as follows. Part 2 explains the theoretical framework. Part 3 elaborates on the applied methodology. The actual analysis is presented in part 4 and the discussion of research results in part 5. We conclude in part 6. 
Lies Van Cauter Lies.VanCauter@soc.kuleuven.be

\section{Theoretical framework}

Sauer sees ISs as the product of a process which is open to flaws. The process by which a project organisation initiates, develops, implements and operates an IS is problematic. An IS process consists of both an innovation and a support management process. In the innovation process there are many uncertainties resulting from a variety of contextual sources. Support management aims for the project organisation to be able to sustain support to continuously pursue the innovation process. If the accumulation of problems results in too little support, this jeopardizes the continuation of the innovation process. If this happens the IS process fails entirely [22].

Sauer distinguishes a triangle of dependences: a system serves stakeholders, stakeholders support the project organisation and the project organisation innovates the system. The starting point to think about problems of the IS process, is this triangle of dependences. In order to analyse their situation, practitioners may start with a double analysis. (1) The needs analysis will define the problems to be solved, the context and the available problem solving mechanisms. This should be followed by (2) a supportpower analysis to determine who has the power to provide the required support.

\subsection{Needs analysis}

The project organisation's needs analysis will consist of two parts: a) an analysis of problems and b) an analysis of the required support to solve these problems:

a) Analysis of problems is twofold: it first maps what problems need to be solved and second a context scanning is done. Context helps to define problems but constraints originating in this context may make the innovation process problematic. The context is analysed along six dimensions: 1 . human factors, 2 . history, 3. technological process, 4. structure, 5. politics and 6. environment. Environment is further subdivided in: 6.1. customers, 6.2. suppliers, 6.3. competitors, 6.4. technology, 6.5. regulators, 6.6. interests and 6.7. culture.

b) The analysis of support looks at available problem-solving mechanisms [22].

Every G2G IS project is confronted with a series of problems. IS success/failure depends on how management tackles problems and on the effectiveness of collaboration. In the project organisation the idea champion takes up this important management task.

\subsection{Support power analysis}

Several questions pop up while doing a support power analysis: Who is able to provide the support identified in the needs analysis? What other relations are likely to affect stakeholders? Will there be competition for the support? [22].

Innovating G2G IS projects does not only involve the creation of new technical systems but also involves lots of other factors, such as a potential change in organisational structure, culture and power discourses. An example of such other factors is that costs and benefits may not be evenly divided: some stakeholders may win and some may lose during (un)intended trade-offs [10], [19]. Insight in power asymmetries also contributes to an improved understanding of IS projects [6]. Information and 
ICT are important resources which organisations use to protect their interests [3]. The idea champion therefore depends on other stakeholders, who may feel that their own objectives are not sufficiently reflected and will therefore frustrate or even sabotage the project planning. Only when these other stakeholders are involved in the project they may recognize their ideas in the problem solution and support the process. This illustrates the need for a process approach [28], [5].

This support-power analysis may be applied at any stage of a G2G IS project. Sauer [22] advices to regularly analyse changes in context and process.

\section{Methodology}

\subsection{Data collection}

In 2012 we interviewed 20 experts of G2G IS projects in Flanders (Belgium). Two years later we conducted focus groups with 32 idea champions of G2G ISs. When the results of both studies are compared, recurrent problems for managing G2G ISs pop up. Considering this, we assume that these problems are rather structural and widespread for G2G IS projects in Flanders. We use Sauer's 'needs and support-power analysis'-framework as a basis for structuring our findings.

Our study mainly focuses on vertical G2G IS projects, meaning projects that span hierarchically related governance levels. Belgium is a state with a complex three layer structure. A top consisting of the federal state and the regions (Flanders, Wallonia and Brussels), a second layer consisting of the provinces and finally a third municipal layer. In this paper we focus on IS projects between the region Flanders and municipalities, possibly involving provinces as well. At regional level, different Flemish departments may be involved in these vertical G2G ISs. We further describe the purpose, sampling and data gathering technique of both data collection exercises.

\section{Interviews 2012}

In order to explore the state of affairs and possible problems, we interviewed 20 experts in 2012 who are known for their knowledge of the Flemish G2G IS field. For the sampling, interviewees were selected based on the snow ball method [1]. They worked for 14 different public organisations at all governmental levels (federal, Flemish, provincial and local). This selection was based on the fact that some organisations were known for successful G2G information sharing, others represented a subset of provincial and local governments, while a third group performed projects to optimise or evaluate G2G information sharing in practice. Data was collected by means of exploratory interviews in which we asked for the most important G2G ISs and to sketch the latest G2G IS trends and potential problems. The advantage of standardized open ended interviews is that these provide a richness of details, may give the researcher perspectives she did not consider before and reduce the risk that the respondent is led in a certain direction. All interviews lasted between 1-2 hours and were fully transcribed.

\section{Focus groups 2014}

To investigate whether additional problems of IS failure could be detected, data 
Lies Van Cauter Lies.VanCauter@soc.kuleuven.be $\triangle$

was collected from Flemish idea champions by means of Focus Groups (FG). FG represent a qualitative research method where participants are selected and brought together to discuss a specific topic [4], [14]. The last decade FGs are gaining acceptance in IS research [4]. This confirmatory research effort allowed for more structural data collection. IS failure is the result of a mesh of socio, technical and organisational complexities in a dynamic context. The FG method is effective in studying these as it defies to reduce a problem to few variables [2]. In 2012 we created an inventory of Flemish G2G IS as an overview was lacking. Out of this inventory, we selected 40 G2G idea champions. The selection was purposive: we chose for a midmanagerial level since this is high enough for capturing strategic aspects and motives, and low enough to identify specifics of implementation and outcomes [2].

We organised 5 FG sessions of 6 or 7 people in a building that was familiar to the participants. Five people did not show up. A group size of 6 to 8 people is optimal. [13]: small enough to let everybody talk, large enough to display diverse opinions. The participants formed a diverse but homogenous group. They all (had) managed a G2G IS project in Flanders. We combined managers of project on personal, geographic and 'business' data in order to cover a wide variety of situations.

To ensure the quality of the data gathering, a question route was developed to foster consistency [9]. The questions were pretested on two IS researchers and an IS layman. During a session of 2 hours the moderator asked several open questions in an informal open atmosphere. Participants were asked to introduce themselves and got an ice breaking question. The moderator introduced the session schedule, explained how the respondents were selected and emphasized that no judgements would be made. We started with general questions and moved on to four key questions [13]: (1) When does an IS have added value? (2) What may stimulate or block an IS project? (3) Which characteristics of the public sector are judged to be different from the private sector? (4) What would you advise a future manager of a G2G IS? Dominant participants were asked to listen, silent ones to speak up [4], [9]. The moderator showed an encouraging body language. Before ending she asked for additional remarks. Finally the main points were summarised and people received a small gift.

One criticism on the FG method is that it is too dependent on the moderator's skills. The moderator was a $\mathrm{PhD}$ student, but the presence of a senior researcher with FG experience ensured a 'back-up'. This researcher took up the role of assistant moderator by taking notes, observing nonverbal behaviour, guarding time and summarising the session. All sessions were audio recorded. A student was present to manage the voice recording and transcribed these afterwards. Another criticism is that negative group dynamics might pop up. People tend to say what they feel is expected of them. To prevent this, a five minute write-down exercise on post-its was done for every key question. This forced participants to get involved [4]. We used a flip chart to organize the post-its but tried to limit the attention drawn to the moderator [13].

\subsection{Data analysis method}

The interview and FG questions were not based on a specific theoretical model so that the data could speak for itself (an inductive approach). A bottom up approach was used to discover a series of problems. A five-staged analysis framework was adopted 
Lies Van Cauter Lies.VanCauter@soc.kuleuven.be $ه$

to interpret the raw data [14]: (1) Familiarisation: Reading transcripts to get the whole picture, major themes emerge. (2)Themes: Concepts arise from text, categories are developed. Analysis happens via a questioning route. (3) Indexing: Sifting data, highlighting quotes, comparing within and between cases. (4) Charting: Re-arranging quotes under new codes. Comparing to reduce data. (5) Mapping \& interpretation: making relationships quotes and links between the data.

We coded all data systematically in Nvivo, a qualitative data analysis software tool. In total, the collected data consisted of 287 pages of interview and FG transcripts. This data was analysed in two stages. During a first analysis the problems that came out of the interviews in 2012 were compared to those detected via the FG research in 2014. Several problems reoccurred, concerning political, technological, economic and juridical issues. During a second analysis the coded data was compared to Sauer's framework by applying the needs and support analysis framework.

\section{Analysis}

The data analysis revealed problems concerning political, technological, economic and juridical issues. Due to space limitations this article only presents 3 political and 5 technology related problems that seemed the most prominent in a Flemish G2G context. In the next paragraphs these eight recurrent problems will be discussed:

We will describe per problem, a) what systematic problem solving needs to be undertaken (= problem description), b) the context elements that have an influence on the needs $(=\underline{\text { context }}$ ) as well as c) the (potential) problem solving mechanisms or support (difficulties) of relevant stakeholders (=support). As several context elements are relevant per problem, these were numbered and we moreover indicate between brackets which context category is applicable. In the description of the support the numbers refer to the previous context elements in order to motivate which support element relates to which element of the context.

\subsection{Political and administrative agreements}

\section{Problem 1: Skilled idea champion}

Problem description. Who should take the lead when you work in an intergovernmental project? A manager, called the 'idea champion' should act as project sponsor and leader for the G2G IS project.

Context. (1)The power of an idea champion partly depends on his hierarchical position and Flemish idea champions often appeared to work in the lower segment of the Flemish government (structure). (2)The respondents believe that an idea champion should have a sufficient skill level. As an example, in terms of IT-knowledge, the Flemish government outsourced most IT profiles during New Public Management reforms. As a result, there is a structural shortage of IT-knowledge (structure). (3)The respondents experience that another relevant skill for an idea champion is a spirit of realism. Managing a G2G IS is intense and several respondents suffered in the past from a burn out (human factors). (4) Creating trust is an essential skill for an idea champion (human factors). Stakeholders take past experiences into account, and it is therefore hard to restore damaged trust (history). One respondent remarked: "We became the victim of our openness, the IS was developed to gather scientific data. 
Lies Van Cauter Lies.VanCauter@soc.kuleuven.be $\longrightarrow$

After 4 years it was suddenly decided to tax us based on the data in the IS."

Support. (1)The respondents believe politicians could make idea champions less vulnerable for sabotage by appointing top civil servants (2) Politicians try to solve the shortage of IT professionals by creating an IT pool via the 'Flanders Connect' initiative. (3) Politicians can support an idea champion by not pushing for unrealistic deadlines (4) A difficulty is that damaged trust hampers future support.

\section{Problem 2: User involvement}

Problem description. Many Flemish departments require data from local governments.

Context. (1)The Flemish government has a tradition of top down treatment of local users instead of considering them as equal partners (culture). (2) Local governments complain of an information asymmetry: they provide data to the Flemish government but get no feedback on what happens with it (culture). (3)The ability of a potential user to cooperate partly depends on the mandate from his own organisation (politics).

Support. (1) According to the respondents, involving local governments from the start might enlarge their willingness to support the system. While doing so the idea champion must guard the overall vision, as intense user involvement holds the risk of scope creep via (un)intended change requests. (2) According to claims in policy documents, Flemish politicians intend 'to treat municipalities less shabbily'. (3) Respondents insisted that municipal politicians should support G2G information sharing.

\section{Problem 3: Top management support}

Problem description. Long term existence of an IS requires top management support, or, in case of G2G IS, top political support.

Context. (1)Politicians may make deficient IS ineradicable. Respondents notice that they have a stake in continuing the system or fear the opposition's criticism (politics). (2)The respondents experience that Flemish politicians often pay no attention to IT (politics). (3)Politicians could exercise a social pressure on Flemish stakeholders to cooperate, but they don't (human factors). (4) Currently an overall political vision is lacking, no party is responsible for G2G IS e-government. There is a lack of coordination between Flemish departments partly due to New Public Management reforms (politics). (5) Because of that the principle of 'gathering data only once' is often violated (environment), (6) which creates a local IS fatigue (history).

Support. (1) Some widely unsupported ISs are kept alive by top management. (2\&3) To succeed, an idea champion needs to strive for support from the highest levels. Top management support helps to convince other stakeholders. Respondents notice that Flemish departments led by ministers of the same political party, support an IS more easily. (4) Recently Flemish ministers announced a fusion of several e-gov. divisions. (5\&6) Local governments are tired of providing support to a whole bunch of Flemish G2G IS systems that request the same data over and over again.

\subsection{Technological agreements}

\section{Problem 4: Business case analysis}

Problem description. The initiation of ISs must be well-prepared, a business case needs to be made that describes the added value, challenges, strengths and weaknesses of an IS, reengineering possibilities and competitive systems in the environment. 
Context. (1) The respondents claim that for a long time making a business case and reflection about the added value for local users was rather rare (culture). (2) Business process reengineering is sometimes skipped because of a lack of time or to prevent adaptions to complex legislation (regulators). Processes are digitized 'as is'.

Support. (1) The respondents believe that if you expect local users to share their data and provide support, they should gain some benefit in return. (2) A low effort expectancy would raise stakeholders' support for reengineering efforts.

\section{Problem 5: IT infrastructure}

Problem description. The IT infrastructure and processes of public organisations can be highly incompatible. These have to be aligned to share data.

Context. (1) In the past, local governments were regularly asked to re-enter data in Flemish ISs because of interoperability problems. Local governments now agree to use the 'Open Standard for Linked Governments', and the Flemish government can translate data to its own standards (technology). (2) Some interoperability problems remain as municipalities cooperate with 4 major vendors who fail to make their products interoperable. They are also path dependent to previous IT investments (history). Support.(1\&2) Stakeholders will more easily support a G2G IS if the effort to achieve interoperability is low. Stakeholder agreements about standards are hereby helpful.

\section{Problem 6: Relationship with developers}

Problem description. IS development requires developers, either in-house or external. Context. (1) Because of the structural outsourcing of IT profiles, it is hard to knowledgeably audit public tenders. Sometimes a third party is hired to evaluate these tenders (history). (2) Development is often solely left to IT'ers because of a lack of the project manager's competence and a political disinterest (structure $\&$ politics).

Support. (1\&2) The structural power imbalance between Flemish idea champions and developers needs to be restored. Currently, respondents have the feeling to buy a pig in a poke: "If you are not a programmer, you cannot always estimate if a task really requires several days. You just have to believe what they say."

\section{Problem 7: Planning}

Problem description. Development by plans is advisable to prevent exceeding budget and time.

Context. (1) Flemish politicians want quick results and dare to set unrealistic deadlines (politics). (2) A project plan consists of design, implementation, testing \& documenting. Respondents experience that testing is unpopular. But the agile approach, based on regular tests, gains importance with Flemish idea champions. Incremental modular steps are preferred in a G2G context. They believe that missing documents are a common problem. Money is rather spend on bug fixing (technological process).

Support. (1) Respondents believe it's better not to release an IS too soon, otherwise it will suffer from bugs and loose support. (2) The agile approach can be a means to involve stakeholders and make them reaffirm their support. But stakeholders do not always know what they want. Respondents think a visionary idea champion is required to prevent scope creep: "The developer gets desperate. Do I have to break down what they asked me to build last month? Let stakeholders participate but make them realise that every question has a cost." 
Lies Van Cauter Lies.VanCauter@soc.kuleuven.be

\section{Problem 8: Security}

Problem description. G2G ISs need to be secured from unauthorized access.

Context. (1) Security efforts are scattered; every local government has vulnerable servers (technological process). (2) Login procedures of Flemish IS are not aligned (technology).

Support. (1)The protection of a G2G IS is as strong as the weakest link. The respondents believe much could be gained if governmental stakeholders would combine efforts in a well-protected shared government cloud. (2)Flemish departments could agree upon login procedures.

\section{CONTEXT}

\begin{tabular}{l|l} 
HUMAN FACTORS & TECHNICAL PROCESS
\end{tabular}

- Idea champions suffer from a rather high - Agile Development gaining ground vs burn out rate

- $\quad$ Trust building skill important unpopular testing

- Social pressure politicians/ cabinet

- Missing documentation

HISTORY

- $\quad$ Local fatigue about Flemish G2G IS

- Hard to restore damaged trust

- $\quad$ Path dependency on local vendors

- Structural shortage and outsourced IT profiles / hard to audit public tenders

\begin{tabular}{|c|c|}
\hline & chy \\
\hline & $\mathrm{PO}$ \\
\hline $\begin{array}{l}\text { - } \text { Culture: top down / no feedback on data } \\
\text { usage/ no business case / added value us- } \\
\text { er forgotten } \\
\text { - } \quad \text { Customers: scope creep } \\
\text { - } \quad \text { Regulators: complex legislation } \\
\text { - } \quad \text { Technology: lack of interoperability } \\
\text { standards / different login procedures }\end{array}$ & $\begin{array}{ll}\text { - } & \text { No overall coordination G2G IS } \\
\text { - } & \text { Ineradicable deficient IS } \\
\text { - } & \text { Lack of coordination Flemish IS due to } \\
\text { - } & \text { DPM reforms } \\
\text { - } & \text { Unrealistic deadlines } \\
\text { - } & \text { Mandate organisation potential users } \\
\end{array}$ \\
\hline
\end{tabular}

Table 1 Overview context constraints of Flemish G2G IS projects

\section{Discussion}

Eight recurrent problems for Flemish G2G IS projects were uncovered: politicaladministrative agreements have to be made to prevent problems with (1) idea champion skills, (2) user involvement and (3) top management support. Agreements on technology and the technological process are required to prevent problems with (4) the business case analysis, (5) IT infrastructures, (6) developers, (7) planning and (8) security. Each problem on itself is not new, the factor research and project management literature list them too (for an overview see e.g. [15], [21]).

By conducting a needs and support-power analysis, it becomes clear that seemingly controllable problems have a much deeper roots, the resolution of which goes beyond project management. Even more, it seems that context and support elements of the different problems are interrelated: 
Firstly, several elements point to a tendency of Flemish idea champions to merely focus on Flemish interests. In the past they forgot to look at the added value for local users. Local governments are just asked or legally obliged to provide data. They only experience the burden of gathering, importing or re-entering data but are not given the benefits. Due to a lack of feedback, it is not even clear to municipalities what the benefits for the Flemish government are. This contributes to a local G2G IS fatigue.

Secondly, several elements hint to a lack of integration. The principle of 'gathering data only once' is frequently violated as the actions of Flemish departments are not often aligned. No single party is responsible for G2G e-government and IS security efforts are scattered. The lack of business process reengineering or improvement efforts does not help integration of departmental actions any further.

Thirdly, several elements indicate a political disinterest in information systems. This results in outsourced IT skills, underestimated costs, unrealistic deadlines and the installation of indecisive idea champions. Success of Flemish idea champions depends to a significant extent on political choices. There appears to be a misfit between the agenda of Flemish politicians and interests of other G2G IS stakeholders.

Managers must tackle the recurrent problems at their roots, and it seems that mindsets are slowly changing:

Firstly more and more local governments refuse to share data even if this is legally obliged. The main reason is the lack of fulfilment of local self-interest which destroys support and always results in failure. A positive note is that a new mind-set comes to surface. Idea champions start to think and negotiate about potential win-wins and provide incentives to join an IS. We notice a shift from a rather top down project management style towards a more process management based style. Flemish idea champions become more aware that local governments are partners.

Secondly, two recent political decisions seem to point out a rising awareness of politicians towards a lack of coordination. Namely the introduction of an IT pool and the fusion of several e-government divisions. It is too soon to conclude whether these decisions will have the desired effect.

Thirdly the new Flemish government claimed the ambition in its coalition agreement to go 'radical digital' by 2020. It aims to do its transactions with local governments solely via digital channels. Whether this points to an enlarged political interest in information systems, has to be seen to be believed. Previous coalition agreements aimed digitization too, mostly without fulfilling the promises.

Our research focused on Flemish G2G IS projects but we notice that researchers in the Netherlands experience similar problems. The recent 'Elias-commission' study [29] on IS failure in the Netherlands also detects a lack of political ICT awareness, a poor estimation of IS costs, the problem of ineradicable insufficient ISs and that no single party seems responsible for G2G ISs (top management support). A lack of risk estimation, no business case nor attention for the added value of other stakeholders were mentioned too (business case analysis). The Dutch colleagues also experience a lack of IT experts in government (skilled idea champion). Like their Flemish colleagues, Dutch idea champions notice a power asymmetry with developers as well as a lack of documentation and the need to use standards (relationship with developers). 


\section{Conclusion and future research}

In this paper we studied the roots of eight recurrent problems of Flemish G2G IS. We aimed to extend the body of knowledge by investigating how local contingencies and support-power relations affect the likelihood of failure of Flemish G2G IS projects. Based on our research we can confirm that the needs and support power analysis of Sauer provides additional insights for G2G IS management in Flanders. It adds a new piece to the complex IS failure puzzle by providing the insight that apparently controllable risks have deeper roots. A focus on Flemish interests by idea champions, political disinterest in technology and a lack of coordination discourage local stakeholders to support Flemish G2G IS projects.. Like [10] we believe that future Flemish G2G IS idea champions should not only deal with potential problems but also pay attention to their context and support power interactions (process management).

By no means we attempted to map all context and support power issues. We targeted to enlarge the understanding of the eight Flemish reoccurring problems. It goes without saying that more context and support factors will be found when a specific G2G IS is studied on a micro level. Every IS innovation is slightly different, no two contexts can ever be exactly the same [12].

Future research might further explore similarities and differences in the G2G IS context of Flanders and the Netherlands and other countries or regions.

\section{References}

1. Arksey, H. \& Knight, P.: Interviewing for Social Scientists: An introductory Resource with examples, Sage Publications: London (1999)

2. Barzilai-Nahon, K. \& Scholl, H.J.: Siblings of a Different Kind: E-Government and ECommerce. Lecture Notes Computer Science, 6228, 25-37 (2010)

3. Bekkers, V.: Flexible info. infrastructures in Dutch E-Gov. collaboration arrangements: Experiences \& policy implications. Government Information Quarterly, 26, 60-68 (2009)

4. Belanger, F. \& Tech, V.: Theorizing in Information Systems Research: using focus groups, Australasian Journal of Information Systems, 17(2), 109-135 (2012)

5. De Bruyn, H., ten Heuvelhof, E. \& in 't Veld, R.: (Process Management, Why Project Management Fails in Complex Decision Making, Springer, Heidelberg (2010)

6. Dwivedi, Y.K., Wastell, D., Laumer, S., Zinner Henriksen, H., Myers, M.D., Bunker, D., Elbanna, A., Ravishankar, M.N. \& Srivastava S.C.: Research on IS failures and success: status update and future directions. Information System Frontiers, Springer. (2014)

7. Dwivedi, Y.K., Ravichandran, K., Williams, M.D. et al (2013). IS/IT Project Failures: A Review of the Extant Literature for Deriving a Taxonomy of Failure Factors. Y.K. Dwivedi et al. (Eds.): TDIT 2013, IFIP AICT 402, pp. 73-88, Springer, Heidelberg (2013)

8. Gil-Garcia, J.R., \& Pardo, T.A.: E-government success factors: Mapping practical tools to theoretical foundations. Government Information Quarterly, 22, 187-216 (2005)

9. Greenbaum, T. L.: Moderating focus groups, a practical guide for group facilitation. Sage Publications, London, 1-249 (2000)

10. Homburg, V. \& Bekkers, V.: Back-Office of E-gov., Managing Information Domains as Political Economies. 35th Hawaii International Conference on System Sciences (2002)

11. Janssen, M., van der Voort, H., \& van Veenstra, A.F.: Failure of large transformation projects from the viewpoint of complex adaptive systems: Management principles for dealing with project dynamics, Information System Frontiers (2014) 
Lies Van Cauter Lies.VanCauter@soc.kuleuven.be $\triangle$

12. Klein, H.K. \& Myers, M.D.: A set of principles for conducting and evaluating interpretive field studies in information studies. MIS Quarterly 23(1), 67-94. (1999)

13. Krueger, R. \& Casey, M.A.: Focus groups, a practical guide for applied research, Sage Publications, London, (2000)

14. Krueger, R.: Focus groups: a practical guide for applied research, Sage publications (1994)

15. McConnell, S.: Rapid Development. Taming wild Software Schedules, Microsoft Press. (1996)

16. Munns, A.K. \& Bjeirmi, B.F.: The role of project management in achieving project success. International Journal of Project Management, 14(2), 81-87 (1996)

17. Nelson, R.R.: Project retrospectives: Evaluating Project Success, Failure and Everything in Between. MIS Quarterly, 4(3), 361-372 (2005)

18. Orlikowski, W.J.: The sociomateriality of organisational life: considering technology in management research. Cambridge Journal of Economics, 34, 125-141 (2010)

19. Orlikowski, W. J., \& Robey, D.: Information technology and the structuring of organizations. Information Systems Research, 2(2), 143-169 (1991)

20. Patanakul, P.: Managing large-scale IS/IT projects in the public sector: Problems and causes leading to poor performance. The Journal of High Technology Management Research, 25(1), 21-35 (2014)

21. Petter, S., DeLone, W., \& McLean E.R.: Information Systems Success: The Quest for the Independent Variable Journal of MIS, 29(4), 7-61 (2013)

22. Sauer, C. : Why IS Fail: A Case Study Approach, Alfred Waller Publishers (1993)

23. Sauer, C., Southon, G. \& Dampney, C.N.G: Fit, failure and the house of horrors: toward a configuration theory of is project failure. Eighteenth International Conference on Information systems, 349-366 (1997)

24. Sauer, C. \& Reich, B.H.: Rethinking IT project management: Evidence of a new mindset and its implications. International Journal of Project Management, 27, 182-193 (2009)

25. Scholl, H.J., Kubicek, H., Cimander, R., \& Klischewski, R.: Process integration, information sharing, and system interoperation in government: A comparative case analysis. Government Information Quarterly, 29(3), 313-323 (2012)

26. Shah, S., Khan, A.Z. \& Khalil, M.S.: Project Management Practices in e-Government Projects: A Case Study of Electronic Government Directorate (EGD) in Pakistan. International Journal of Business and Social Science, 2(7), 235-243 (2011)

27. Southon, G., Sauer, S. \& Dampney, K.: Lessons from a failed information systems initiative: issues for complex organisations. International Journal of Medical Informatics, 55, 33-46 (1999)

28. Srivastava, S. C.: Is e-gov. providing the promised returns? A value framework for assessing e-gov. impact. Transforming Gov: People, Process \& Policy, 5(2), 107-113 (2011)

29. Tweede kamer der Staten Generaal: Parlementair onderzoek naar ICT-projecten bij de overheid, Eindrapport vergaderjaar 2014-2015, 33 326, nr. 5, 1-219 (2014)

30. Volkoff, O., \& Strong, D. M.: Critical realism and affordances: theorizing it-associated organizational change process. MIS Quarterly, 37(3), 819-834 (2013)

31. Weerakkody, V., Baire, S. \& Choudrie, J.: E-Government: The Need for Effective Process Management in the Public Sector. 39th HICCS, 1-10 (2006)

32. Winter, M., Smith, S., Morris, P. \& Cicmil, S.: Directions for future research in project management. International Journal of Project Management, 24, 638-649 (2006)

33. Yeo, K.T.: Critical failure factors in information system projects, International Journal of Project Management, 20, 241-246 (2002)

34. Zheng, L., Yang, T.M., Pardo, T. \& Yang, Y.: Understanding the "Boundary" in Information Sharing and Integration. 42nd HICCS, 1-10 (2009) 